\title{
COMPENSATION METHOD IN BOILER DRUM LEVEL MEASUREMENT AND CONTROL
}

\author{
Sundarasekaran $D^{1}$, Dr.Gomathy $C^{2}$ \\ ${ }^{1}$ Research Scholar, Sathyabama University, \\ ${ }^{2}$ Electronics \& Control dept., Sathyabama University. \\ E-Mail: 1d_ssekar@yahoo.co.in
}

\begin{abstract}
The Industrial Boiler Drum Level control loop is to maintain the drum level within the prescribed limit. Simply regulating the Boiler Feed Water Control Valve regulates the boiler drum level. The drum level is measured by using level transmitter. The level signal is compared with fixed set value of level controller. Whenever there is a sudden rise in the steam flow the drum pressure decreases. Due to decrease in the pressure there is a temporary rise in the drum level. This is called as swelling effect. The shrinking effect is opposite to the swelling effect. To avoid these problems this paper suggests the method of pressure temperature compensating method.
\end{abstract}

\section{INTRODUCTION}

The main important control loops are Drum Level Control, Combustion Control, Steam Temperature Control and PRDS. The steam flow is measured and the signal of steam flow is added to level controller's output as a feed forward signal to take care of sudden load changes of boiler. The output of a feed water controller is given to feed water control valve to regulate the feed water to maintain the boiler drum level. Conventionally two control valves are provided in feed water line, one for $30 \%$ and on for $100 \%$. The 30 $\%$ valve is used in single element control. Where as $100 \%$ is used for three-element control. This paper confined to only drum level Temp. Pressure compensated method. Typical Boiler Process Diagram shown in Fig1.

\section{BOILER DRUM LEVEL MEASUREMENT WITH OUT COMPENSATION}

Feed water is fed into the drum is a critical control, either a series of valves in parallel with a series of constant-pressure feed water pumps. If the feed water level in the drum goes too high, water can become entrained in the steam going to the turbine and can cause problems. If the drum feed water level goes too low, the drum itself can become overheated, possibly resulting in problem.

Feed water control has two modes of automatic operation: single- and three-element control. The operator sets the drum level set point for both modes. In single-element control the difference between the drum level and the drum level set point provides the error signal that is used by the single-element controller

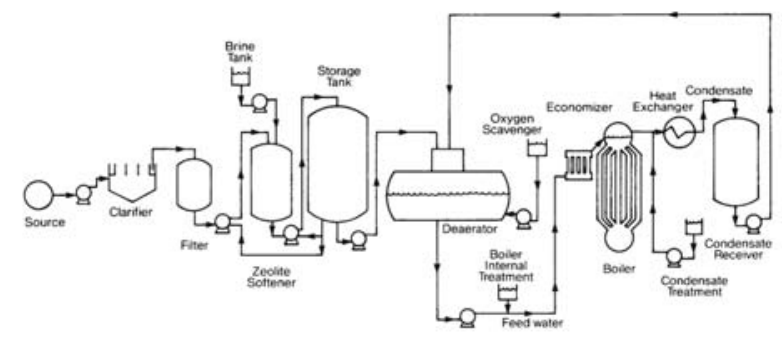

Fig. 1. Typical Boiler Process Diagram

to control the rate of water entering the drum by modulating the feed water flow control valve. Typical Drum Level Measurement and Control with out Compensation shown in Fig.2.

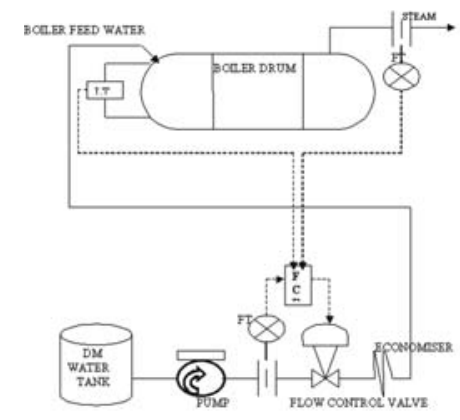

Fig. 2. Drum Level Measurement and Control with out Compensation

Three-element control governs the three variables, or elements, that are used in this control scheme: drum level, steam flow, and feed water flow. Drum level control uses a cascaded controller scheme consisting of an outer and an inner controller. Steam flow is an indication of the rate at which water is being removed from the drum. A function of steam flow is 
used as a feed forward to the outer controller. The outer controller then operates the drum level error on. The output of this controller is the feed water flow set point. The inner controller then operates the difference between this set point and the feed water flow on. The output from this controller is then used to modulate the feed water flow control valve.

Three-element control is much more stable and robust than single-element control. The reason that we use single-element control at all has to do with the nature of the instrumentation. Typically, feed water flow, and occasionally steam flow, is developed by using a flow-measuring device like an orifice plate or a flow nozzle, where flow rate is proportional to differential pressure. However, a problem occurs at low flow rates (low boiler load), where differential pressures are not as solidly proportional as we would like and therefore untrustworthy for boiler control. Consequently, single-element control is used at low loads.

A well-tuned drum level control can be placed in automatic as soon as a pump is started. By the time steam flow has passed $25 \%$ of the total range, we can consider steam flow signals to be reliable. That is a good point at which to switch to three-element control.

Normally, tuning for the single-element controller consists of big proportional and very small integral gain settings. Tuning for the three-element controller has some additional requirements. As in any cascaded loop, it is absolutely crucial that the inner controller be tuned as tightly as time will allow. The inner controller, the feed water controller in this case, must have an integral action that is faster than that of the outer, or drum level, controller (Figure 3). This is true for all cascade loops.

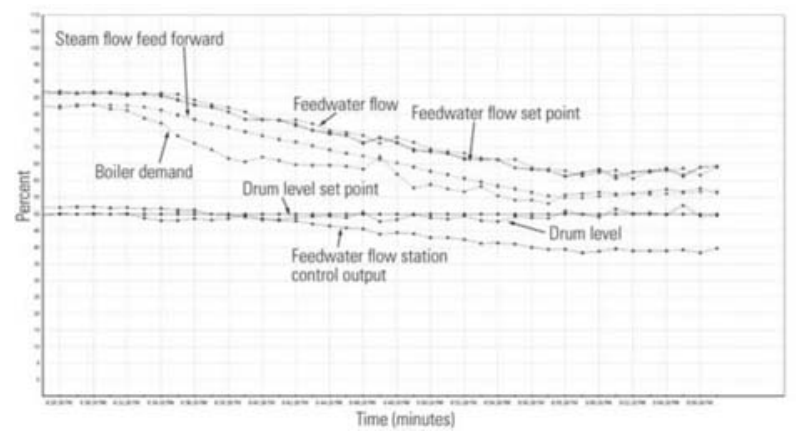

Fig. 3. Typical Controller action Graph

\section{A. Rapid Control}

A typical oil-fire boiler with a properly tuned drum level control will respond very quickly to a substantial load increase (top) or load decrease (bottom). The dynamic response of other key variables in boiler drum level control system is also illustrated. Source: Tim Leopold. You may notice that as the load decreases, the drum level sags downward, and as the load increases, the drum level is slightly elevated. This means that the steam flow feed forward is just a tad too strong. A minute adjustment to the feed forward signal can add stability to the control loop

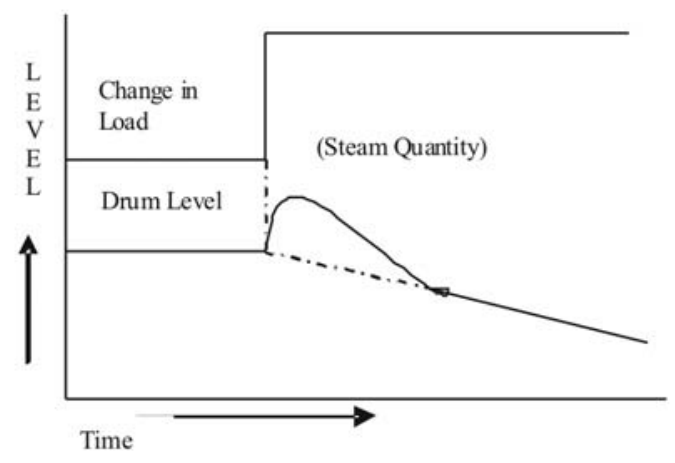

Fig. 4. Drum Level Charactertics for Rapid Load Changes

The boiler drum level responds in an integrating manner to the steam and feed water flow, but the response reverses shown in fig.4. When the amount of steam supplied increases rapidly. When the steam flow increases rapidly, drum pressure falls and the liquid in the drum boils over.

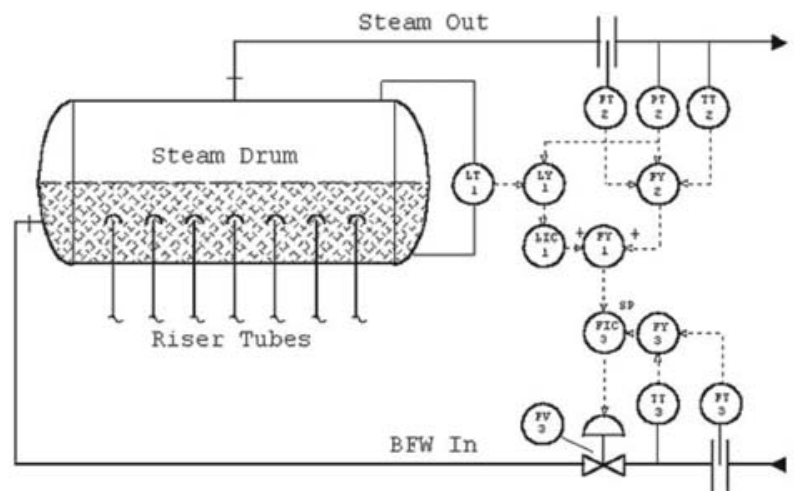

Fig. 5. Schematic Process Diagram of Three-Element Control

The single loop programmable controller for drum level control can perform cascade control for drum level and feed water, reduce fluctuations in feed water 
pressure, improve feed water charactertics and also perform three element control- drum level, feed water flow and main steam flow-using the main steam flow signals as a feed forward signal. In addition this controller includes another drum level control function that permits drum level feed water control to be selected during system start up. Advanced single loop computational function enable drum level pressure compensation.

\section{B. Three Element Control}

The drum level is affected by fluctuations in the main steam flow. Typical three-element control shown in fig.5. To make the feed water flow rapidly follow the main-steam flow, three-process signals-drum level, feed water flow and main steam flow signals are used. This is called three element control of deviation signal is given by

$$
\varepsilon=(F w-F s)=K-L o
$$

Where

$\mathrm{Fw}=$ Feed water signal,

Fs = Main steam flow signal

$\mathrm{K}=$ Constant

$\mathrm{L} 0=$ Drum level control unit output

The equation 1 represents that if a deviation between the feed water flow and main steam flow occurs a corrective action is executed before a drum level fluctuates

\section{Single element Control}

When the boiler starts up, the feed water and main steam flow fall below the low limit, resulting in unstable. Cascade control for Level Indicating Control and Flow Indicating Control using three-element control. For stable cascade control, single element control using drum level controller without a feed water flow controller is recommended and can be used to directly control the feed water control valve. Bump less transfer between three elements control and single element control are possible.

\section{DRUM LEVEL PRESSURE COMPENSATION}

The steam in the drum as well as the density of water in the drum varies with the drum pressure and this can disable level measurement from the differential pressure transmitter. Using advanced computational functions the single loop programmable controller compensates for the differential pressure signal to provide a correct level signal.

\section{A. Drum Level Measuring Principle}

Drum level differential pressure signal, (ÄP) depends upon the steam in the drum, head pressure $(\mathrm{H})$ and the head pressure $(\mathrm{L} 1)$ in the wet leg. Refer fig.6.

Refer equation. 1,

$$
h m=\frac{\Delta P+(Q a-Q s) H}{(Q w-Q s)}-h_{0}
$$

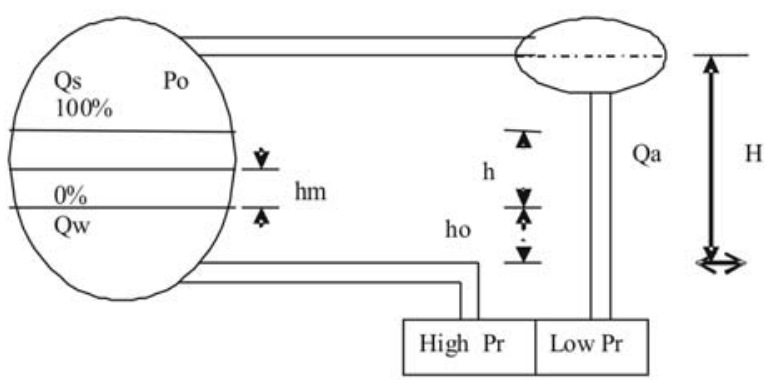

Fig. 6. Drum Level Measurement with Wet Leg

Where

$\mathrm{hm}=$ Actual Drum Level

$\Delta \mathrm{P}=1$ Drum Level Measuring $\Delta \mathrm{P}(\mathrm{mmwc})$

$\mathrm{Q}=$ Wet Leg Density $\left(\mathrm{g} / \mathrm{cm}^{3}\right)$

Qs = Saturated Steam Density $(\mathrm{g} / \mathrm{cm})$

$\mathrm{Qw}=$ Saturated Water Density $(\mathrm{g} / \mathrm{cm})$

$\mathrm{H}=$ Wet Leg Height ( $\mathrm{mm}$ )

B. Drum Level Pressure Compensation:

Level Signal After Pressure Compensation

$$
=\frac{(X 1-P 09-P 10)+P 08^{*} F(x)}{G(x)} P 11
$$

Where,

X1 = Drum Level Signal

P09 = Drum Level Scaling Parameter 
P10 = Drum Level

P08 $=$ Wet Leg H setting Parameter

P11 $=10 \%$ Level h0 Setting Parameter

$F(x)=(Q a-Q s)$ Characteristics for change in pressure

$\mathrm{G}(\mathrm{x})=(\mathrm{Qw}-\mathrm{Qs})$ Characteristics for change in pressure

If the equation 2 is divided by the drum level span $h$, the following equation is obtained.

$$
\frac{h m}{h}=\frac{(\Delta P / h)+(Q a-Q s H / h)}{(Q w-Q s)}=\frac{h 0}{h}
$$

Since equation 3 is related to equation 4 the following parameters can be obtained,

$$
\begin{aligned}
& \mathrm{P} 09=\frac{\Delta \mathrm{P}_{\text {max }}-\Delta \mathrm{P}_{\text {min }}}{H} \\
& \mathrm{P} 10=\frac{\Delta \mathrm{P}_{\text {min }}}{\mathrm{H}} \\
& \mathrm{P08}=\frac{H}{H} \\
& P 11=\frac{h 0}{H}
\end{aligned}
$$
$\Delta \mathrm{P}_{\max }$

Where Level transmitter range $=\Delta \mathrm{P}_{\min }$ to

C. Determining Drum Level Transmitter Measuring Range:

Drum Level transmitter measuring range must remain within the level transmitter measuring range even when the drum pressure changes.

To insure this, processed as follows,

Level transmitter range $=\Delta P_{\min }$ to

$$
\begin{gathered}
\Delta P_{\max }=\Delta P_{\min }=h o(Q w-Q s) m m \\
H(Q a-Q s)_{\min } \\
\Delta P_{\max }=(h+h 0)(Q w-Q s)_{\max } ; H(Q a-Q s)_{\max } \ldots
\end{gathered}
$$

Where
$\Delta \mathrm{P}_{\min }=\Delta \mathrm{P}_{\text {(mmwc) }}$ which produces $0 \%$ output at the level transmitter.

$$
\Delta P_{\max }=\Delta P_{(\text {mmwc })} \text { which produces } 100 \% \text { output }
$$
at the level transmitter.

$$
\begin{aligned}
\text { h0 } & =\text { drum } 0 \% \text { level }(\mathrm{mm}) \\
h & =\text { level measuring span }(\mathrm{mm}) \\
H & =\text { wet leg height }(\mathrm{mm})
\end{aligned}
$$

$\mathrm{Qw}=$ saturated water density $(\mathrm{g} / \mathrm{m})$

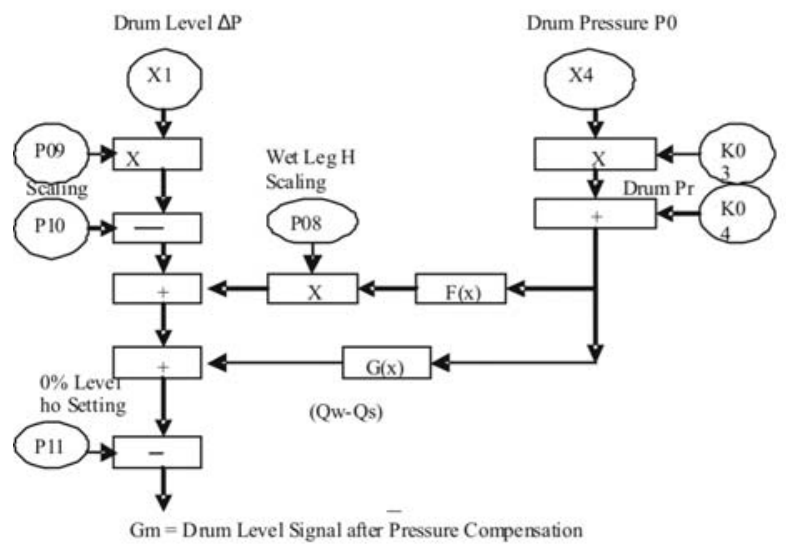

Fig. 7 Drum Level Pressure Compensation Block Diagram

Qs = saturated steam density $(\mathrm{g} / \mathrm{cm})$

$\mathrm{Qa}=$ wet leg density $(\mathrm{g} / \mathrm{cm})$

D. Determining $F(x)$ and $G(x)$ characteristics for Drum Level Pressure Compensation:

To determine these characteristics select either $100 \mathrm{~kg} / \mathrm{cm}^{2} \mathrm{G}$ or $200 \mathrm{~kg} / \mathrm{cm}^{2} \mathrm{G}$ depending upon the range of differential pressure variations. Refer fig.7 and 8.

Table 1.1: Variations of water densities with drum pressure.

\begin{tabular}{|c|c|c|}
\hline $\begin{array}{c}\text { SI. } \\
\text { No. }\end{array}$ & $\begin{array}{c}\text { Drum pressure } \\
\mathrm{Kg} / \mathrm{cm}^{2}(\mathrm{G})\end{array}$ & $\begin{array}{c}\text { Water density } \\
\mathrm{Kg} / \mathrm{m}^{3}\end{array}$ \\
\hline 1 & 19 & 849.900 \\
\hline 2 & 20 & 846.843 \\
\hline 3 & 21 & 843.855 \\
\hline 4 & 22 & 840.939 \\
\hline
\end{tabular}




\begin{tabular}{|c|c|c|}
\hline $\begin{array}{c}\text { SI. } \\
\text { No. }\end{array}$ & $\begin{array}{c}\text { Drum pressure } \\
\mathrm{Kg} / \mathrm{cm}^{2}(\mathrm{G})\end{array}$ & $\begin{array}{c}\text { Water density } \\
\mathrm{Kg} / \mathrm{m}^{3}\end{array}$ \\
\hline 5 & 23 & 838.080 \\
\hline 6 & 24 & 835.300 \\
\hline 7 & 25 & 832.568 \\
\hline 8 & 30 & 822.165 \\
\hline 9 & 35 & 810.044 \\
\hline 10 & 40 & 798.658 \\
\hline 11 & 45 & 787.959 \\
\hline 12 & 50 & 777.725 \\
\hline 13 & 60 & 758.322 \\
\hline 14 & 70 & 739.918 \\
\hline 15 & 80 & 722.386 \\
\hline 16 & 90 & 705.268 \\
\hline 17 & 100 & 688.420 \\
\hline 18 & 110 & 671.727 \\
\hline 19 & 120 & 654.964 \\
\hline 20 & 130 & 638.080 \\
\hline 21 & 140 & 620.886 \\
\hline 22 & 150 & 603.172 \\
\hline 23 & 160 & 584.692 \\
\hline 24 & 170 & 565.099 \\
\hline 25 & 180 & 543.507 \\
\hline
\end{tabular}

E. Determining the Controller section:

The flow signal from differential pressure transmitter is corrected for pressure and temperature. Input signals from each detector are fed in to the controller. The controller inputs, differential pressure, pressure and temperature is used to compute the compensated flow process variable. The controller performs control computations and outputs the manipulated variable. Refer fig9.

2. Simple PID control is implemented in this example.

3. The Temperature-Pressure Compensation expression is as follows,

$$
Q x=3\left(\left(P f^{*} T n\right) /\left(P n^{*} T f\right)\right) \sup * \Delta P
$$

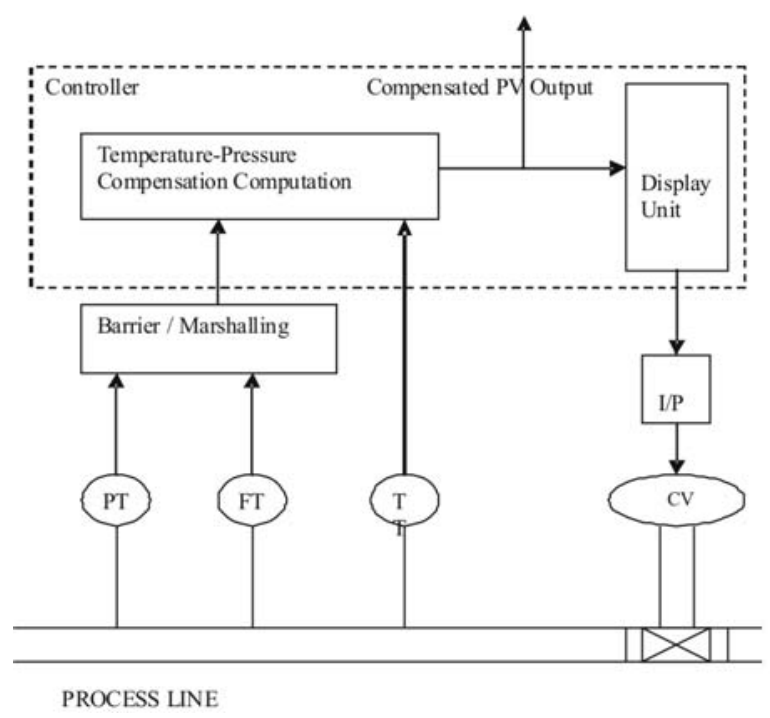

Fig. 9. Flow Control System with Temperature Pressure Compensation

Where,

$\Delta \mathrm{P}=$ Differential Pressure

$Q x=$ Fluid Flow converted to reference conditions

Fig. 8. Water Density vs. Drum Pressure

Example of Temperature - Pressure compensation for Ideal flow control.

This example describes the scaling of the arithmetic compensations and the method of determining the constants.

$P n=$ Orifice design reference pressure expressed as an absolute pressure

$\mathrm{Tf}=$ Working Fluid reference temperature expressed as an absolute temperature 
Each physical quantity is converted to a normalized value in the range 0 to 1 .

$\mathrm{Pf}=\mathrm{P}^{\mathrm{span}}{ }^{*} \mathrm{X} 2+\mathrm{P}_{\min }^{*} \mathrm{X} 2$ : pressure signal 0 to 1

$\mathrm{Tf}=\mathrm{T}_{\text {span }}^{*} \mathrm{X} 3+\mathrm{T}_{\min }^{*} \mathrm{X} 3$ temperature signal 0 to 1

$\mathrm{Qx}=\mathrm{Q}_{\text {span }}^{*} \mathrm{Y} 2(\mathrm{Y} 2=$ compensated flow rate signal 0

$\Delta \mathrm{P}=\Delta \mathrm{P}_{\text {span }}^{*} \mathrm{X} 1(\mathrm{X} 1=$ Differential pressure signal 0 to 1$)$

By substituting normalized signal valves the following expression is obtained.

$$
\mathrm{Q}_{\mathrm{span}}=\mathrm{Y} 2=3\left(\left(\mathrm{~K} 2^{*} \mathrm{X} 2+\mathrm{K} 4\right) /\left(\mathrm{K} 3^{*} \mathrm{X} 3+\mathrm{K} 5\right)\right)^{*} \mathrm{X} 1
$$

Where,

K2 = pressure transmitter span / Orifice Design reference pressure in absolute pressure,

$$
=10 /(6+1.033)=1.422
$$

$K 3=$ Temperature Converter Span / Orifice design reference temperature absolute temperature,

$$
=500 /(300+273.2)=0.872
$$

$K 4=$ Pressure transmitter minimum reading (Absolute Value) / Orifice design reference pressure in absolute pressure, $=(0+1.033) /(6+1.033)=0.147$

$K 5=$ Temperature transmitter minimum reading (Absolute temperature) / Orifice design reference temperature absolute temperature,

$$
=(0+273.2) /(300+273.2)=0.477
$$

by substituting the above,

$$
Y 2=3\left(\left(1.422^{*} X 2\right)+0.147\right) /\left(\left(0.872^{*} X 3\right)+0.477\right)^{*} X 1
$$

The coefficient $\mathrm{Kn}$ in the above expression is all below 8.000

The intermediate data in the computation and the result (value of $\mathrm{Y} 2$ ) from the computation are also below 8.000. Therefore the controller can perform computations.

\section{CONCLUSION}

The Temperature-Pressure compensation method is simple to implement for better drum level control.
This method will be very much effective in the high-pressure boilers in cascade form, so that the steam grid pressure will be maintained without affecting the boilers. Also can be connected with combustion control loop in the boiler. The cost of implementation is very less.

\section{REFERENCES}

[1] Boiler Operation Engineering by P.Chattopdhay, Tata McGraw-Hill Publishing Company Limited,

[2] Applied Instrumentation in Process Industries by W.G.Andrew \& H.B.Williams

[3] Process Control Instrumentation Engineers Handbook by Be'la G.Lipta'k Heinemann

[4] MFL Boiler Operating manual

C. Gomathy acquired a B.E.

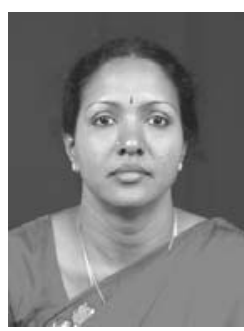
(with honors) degree in Electronics and Communication Engineering from Government College of Engineering, Tirunelveli, in the year 1986, and an M.S. degree in Electronics and Control Engineering from Birla Institute of Technology and Science, Pilani, in 1992. She also obtained an M.S. (by research) degree from Anna University in 2001. She obtained her Ph.D. in the area of Mobile Ad hoc networks from Department of Electronics and Communication Engineering, College of Engineering, Anna University, Chennai, India, in the year 2007. She has published over 408 research papers in National and International conferences and journals. Her areas of interest include mobile ad hoc networks, high-speed networks, and wireless sensor networks.

D.Sundarasekaran, Electronics \& Control dept., Research Scholar, Sathyabama University, B.E.,(Electronics \& Communication), College of Engineering, Guindy, Anna University, M.E., (Electronics \& Control), Sathyabama University, P.G.Dip (Production Mgt.), Annamalai University, Automation Course at Automation College, SINGAPORE, F.I.E., from I E I, (Electronics \& Telecommunication), Member in Indian Institute of Technical Arbitrators, Member, Board of Studies - Electronics, Madras University, Deputed to IRAN by NIOC through GOI for Installation \& Commissioning of Electrical and Instrumentation Systems of 5000 MTD Methanol Plant, Presently Working as Manager -Process Automation, Madras Fertilizers Limited, Chennai-68. 